December 20,1988

\title{
LESSONS FROM DEVELOPMENT ASSISTANCE:
}

IMPLICATIONS FOR AGRICULTURAL AND RURAL DEVELOPMENT

\author{
Vernon W. Ruttan \\ Regents Professor \\ Department of Agricultural and Applied Economics \\ University of Minnesota
}

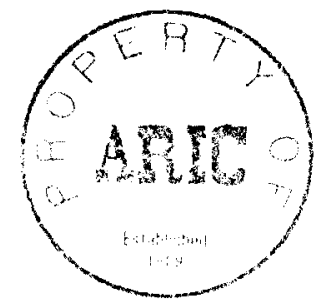

Paper prepared for the 50ih Anniversary Volume

Indian Journal of Agricultural Economics 


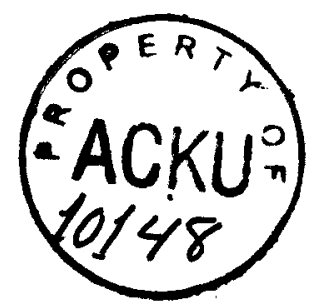

LESSONS FROM DEVELOPMENT ASSISTANCE:

IMPLICATIONS FOR AGRICULTURAL AND RURAL DEVELOPMENT

Vernon W. Ruttan*

Foreign aid as an instrument through which a government attempts to strengthen the economy of another country is a relatively new phenomenon. The Marshall Plan, initiated in 1948, was the first major foreign assistance program. Put together hastily to revive the war-torn economies of Western Europe, the Plan distributed $\$ 13$ billion over a period of four years. It succeeded beyond the greatest hopes of its initiators. This was followed by the commitment, in President Truman's 1949 inaugural address, to a "bold new program for making the benefits of our scientific advances and industrial progress available for the improvement and growth of underdeveloped areas".

By the early 1950s, it was apparent that the Western European economies had achieved such large gains that they would maintain rapid rates of economic growth through their own efforts. By that time, however, the development efforts of the newly independent countries of Asia and the Middle East were attracting attention. It became evident that it was in the interest of American foreign policy to see those development efforts succeed.

In this paper I present some of the generalizations about the impact of development assistance, including the impact of assistance to

\footnotetext{
* Regents Professor, Department of Agricultural and Applied Economics,
} University of Minnesota 
agriculture and rural development, that can be drawn from post-World War II development assistance experience. ${ }^{1}$

\section{Lessons fron Macroeconomic Assistance Policy}

Concessional assistance has typically represented less than 2 percent of the developing countries' GNP. It would be unreasonable to expect that assistance of this magnitude would have a dramatic impact on living standards throughout the developing world. Development assistance has, however, played a critical role in sustaining and enhancing growth rates and improvements in living standards in particular countries during crucial periods in their development process. ${ }^{2}$ It is also clear that the effectiveness of development assistance depends on the policies pursued by both the donor agencies and the recipients.

\section{The Influence of Domestic Economic Policy on the Effectiveness of Donor Economic Assistance}

The effectiveness of economic assistance has been strongly conditioned by the economic policy environment of the host country. It is now generally conceded that economic assistance to Korea and Taiwan was much less effective in generating income growth during the 1950 s and early 1960 s when these countries were pursuing import substitution policies than after they made the transition to export-oriented industrial policies. The contrasting role of domestic economic policy on the effective use of development assistance is illustrated in a particularly striking way in the case of Ghana and the Ivory Coast. Following independence, Ghana chose a policy of socialism and state control. The Ivory Coast adopted a more modest role for the state, viewing its role as influencing and guiding rather than replacing private sector decision making. 
It would be a mistake to view the contrast between Ghana and the Ivory Coast as simply too much or too little planning or too much or too little direct public participation in economic affairs. The intervention of the Ivory Coast in its sugar industry was almost as damaging, as the intervention of Ghana in its oll palm industry. The contrast is between (a) a misguided attempt to determine and control the supply and demand of private goods across a wide spectrum of economic activity in Ghana and (b) a program that provided reasonable incentives for private economic activity along with investment in physical infrastructure and services directed toward enhancing the productivity of the private sector. In addition, Ghana's failure to correct its increasingly overvalued exchange rate, its repression of producer prices of agricultural output, and its establishment of parastatal enterprises in industry distorted its domestic infrastructure investments and led to excessively high capital output ratios in infrastructure, agricultural, and industrial development projects.

Our review of country experience has demonstrated in particular the close linkages between trade policies and the effectiveness of development assistance. There is firm evidence that an export-oriented strategy and rapid growth of exports have been integrally associated with rapid economic growth. There are three reasons for the positive impact of an exportoriented strategy. First, it permits countries to take advantage of comparative advantage, whether based on resource endowments or technology development. Second, it prevents some of the costly mistakes that are often associated with import substitution or other restrictive trade and 
industrial development strategies. Third, it forces governments to adopt policies that lead to better economic performance by the private sector.

External development assistance has at times been very important in providing the economic and technical assistance needed to facilitate the transition to export-oriented policies. Aid-financed infrastructure has also been important in permitting economies such as Korea, Brazil, Taiwan, and Turkey to respond to the incentives that were designed to encourage the transition to an export-oriented economy. Economists associated with both bilateral and multilateral development assistance agencies were also, at times, influential in the policy analysis and discussions that led to the policy reforms.

It is also true that foreign assistance, particularly when motivated by noneconomic policies, has provided countries with the resources needed to perpetuate inefficient economic policies. This was clearly the case in South Korea during the 1950s. The 1950 s period, a time when U.S. economic assistance was essential to Korea's political and economic viability, was characterized by a chaotic multiple exchange rate system, import licensing, and pervasive controls in every sector of the economy. The relatively poor performance of the Korean economy in the 1950s, despite massive aid, was in large part a result of inappropriate trade, exchange rate, and other domestic policies. When these policles were altered in the 1960s, growth accelerated despite lower levels of assistance. American monetary experts, financed by the U.S. aid agency, played an important role in the discussion that led to the monetary and fiscal reforms of the mid-1960s.

The conclusion that the effectiveness of assistance in generating economic growth is severely weakened in the absence of appropriate economic 
policy on the part of the recipient country poses several policy problems for the donor community. A variety of assistance activities can be effective in an environment characterized by a favorable policy regime and substantial administrative capacity. The absence of these conditions severely limits the range of effective assistance activities. These deficiencies are, however, often more severe in the poorest countries were there may be strong equity arguments for providing development assistance even if it is less than fully effective. In such situations assistance should focus on selected sector development activities that will establish the foundations for growth at a time when it become politically and economically feasible for the recipient country to adopt more growthoriented development policies.

\section{Policy Dialogue and Aid Effectiveness}

The effectiveness of economic assistance is influenced by (a) the degree of convergence in the views of aid donor and recipient countries concerning the latter's economic policies and (b) the importance of economic development objectives relative to other donor motivations in decisions concerning the nature and allocation of economic assistance. A convergence of views on the recipient's economic policy can occur only in the context of a donor-recipient aid dialogue. The issue of how much impact policy dialogue associated with development assistance negotiations actually has on host country development policy is extremely difficult to determine. The impact may be quite large during a period when the host country is experiencing economic or political stress, as in Bangladesh immediately after independence, or during a period when both the donor and host governments share common political and economic objectives. 
Policy dialogue between assistance agencies and the government of Turkey during the late 1960s was very influential in bringing about policy reforms that avoided an extreme crisis. French technical assistance personnel played an important role in guiding both macroeconomic and sector economic policy in the Ivory Coast along relatively efficient lines. In the case of Korea, the major impact of donor-host policy dialogue came as the level of donor assistance began to decline.

India is often cited as a country in which attempts to use donor leverage to induce policy reform has been counter productive. In the early 1960 s the World Bank proposed an the government of India accepted a comprehensive study of the causes of the slow pace of Indian economic development. The study produced by the Bell mission was critical of Indian agricultural policy and of the quantitative controls on imports and foreign exchange. The study was followed by a controversial devaluation of the Rupee in 1966. Within India the devaluation was interpreted as an unwarranted attempt by the Aid India Consortium to interfere in domestic policy. ${ }^{3}$

A number of criteria appear to play an important role in the effectiveness of donor agencies' efforts to exercise constructive leverage on recipient country macroeconomic policy. One is that both the donor and recipient country bring substantial professional capacity and experience to the policy dialogue. A second is that the donor agencies be in a position to provide substantial program aid during the period of transition to the new policy regime.

There is clear evidence that a "donor interest" model is more effective than a "recipient need" or "global resource allocation model" in 
explaining the flow of bilateral donor resources. It is also our impression that donor strategic, political, and trade interests are playing an increasingly important role in the allocation of assistance resources. When donor interests strongly influence the flow of aid resources, the effectiveness of policy dialogue is reduced. Donors find it extremely difficult to utilize policy dialogue as a lever to induce better policy in the recipient country when the representatives of that government are aware that the security or trade interests of constituencies in the donor country carry more weight than the policy reform objective. These conflicting pressures create a very difficult environment for the officials in the development assistance bureaucracies of the donor countries.

During the 1980s discussions of donor influence and leverage has been carried out in a more constructive environment than in the 1960 s and 1970 s. Both donor and host country political leadership and constituencies seem to be more aware than in the past that policy dialogue and influence are inherent in the donor-recipient relationship. It is also possible that as a result of past experience some bilateral donors have a more sophisticated understanding of the economic costs of using the limited leverage of development assistance to pursue ideological or political objectives in the recipient country. Nonetheless, noneconomic factors still are an important element of bilateral programs. As a consequence, there is a presumption that multilateral aid, which is not as burdened with these constraints, is likely to be a more effective vehicle for a policy dialogue and for supporting economic development. 


\section{The Influence of Assistance on National Economic Growth}

The macroeconomic impact of development assistance represents a continuing theoretical and empirical puzzle. It seems clear that there are relatively few instances where the flow of development assistance has been large enough to significantly influence aggregate growth rates. This conclusion holds even if rates of return to the resources transferred in the form of development assistance are several multiples of the rates of return that the same investments would earn in the country providing the assistance. It is possible that the literature we have reviewed has underestimated the impact of development assistance on growth; however, the evidence to support a conclusion that development assistance has accounted for major intercountry growth differences is not available.

Generalizations regarding the effects of economic assistance on national economic growth are complicated by the complex economic and political objectives of both the donor and the host country. Where donor country political objectives have dominated economic development objectives, as in the case of U.S. assistance to Korea in the early 1950 s and recent U.S. assistance to Egypt, expectations regarding the impact of assistance on economic growth should be relatively modest. It seems apparent that this conflict in objective is a major source of the difficulty in drawing generalizations regarding the impact of development assistance on growth rates.

A second reason why it has been so difficult to develop empirical evidence on the impact of development assistance on national growth is that, except for short periods, the flow of concessional development assistance has generally been small compared to the sum of national and 
commercial resource flows available to sustain development. Aid flows have contributed importantly to initiating or sustaining the momentum of growth at critical periods. India between 1956 and 1967 and Korea in the first decade after World War II are examples. But there are also failure cases such as in Ghana in the 1960 s and in Tanzania in the 1970s.

\section{Lessons from Assistance for Sector Development}

There is, however, evidence from specific country cases and from sector studies that development assistance has been most effective in generating growth when it has been focused on those investments that enhance productivity growth. Investment in education has been one such investment. Investment in agricultural research has been another.

In this section I attempt to draw some lessons for sectoral development assistance--particularly those areas of sectoral assistance that are relevant for agricultural and rural development.

\section{Assistance for Physical Infrastructure Development}

During the 1950s and 1960s, large-scale investment in transport facilities (roads, railroads, ports, and airports) and multipurpose (power, flood control, irrigation) resource development projects occupied a very prominent place in both bilateral and multilateral development assistance portfolios. Many of these activities made substantive contributions to the development of the recipient countries. Others became a burden on the development process. A number of factors contributed to the low returns realized form such projects. Project cost overruns were often substantial. The time required to complete the projects was often much longer than projected in the planning studies. The technology and scale of such 
projects were often incompatible with the level of technological development in the rest of the economy. Failure to consider the implications of exchange rate distortions led to investments that were excessively capital-intensive or entirely inappropriate. Returns to infrastructure investment were delayed and reduced by policy regimes that were not able to take full advantage of growth opportunities.

Disappointment with the flow of benefits led to severe criticism of large infrastructure projects. In the Seyhan project in Turkey, for example, the production impact of the land and water development programs of the 1950s and 1960s did not exert a major impact on production until the 1970s. In Korea, the payoff to transportation investments made during the 1950s was relatively low until the period of rapid growth in the late 1960 s and 1970 s.

In India, returns on large infrastructure and industrial projects were dampened by failure to invest in appropriate technical education and research. The impact of irrigation investment has often been delayed because of failure to develop on-farm water delivery systems and institutions to manage them (Traxler and Ruttan, 1986).

Over the last several decades, both technical and economic aspects of project planning and evaluation have become more sophisticated. Much has been learned and the methodology and practice of cost-benefit estimation have been developed and applied more widely. Planning and implementation capacity in the aid-recipient countries has improved. The worst errors of the 1950s and 1960s are no longer being made. And a broader and more balanced portfolio of projects embracing technical and professional training, research and development, and others is, in many countries, 
overcoming the lack of the complementary inputs that have in the past dampened the returns to infrastructure project investment.

It now appears possible again to take a more positive view of lending for infrastructure investment, especially in connection with agricultural development. Furthermore, it appears that in a number of countries the enhanced capacity for infrastructure planning and development means that the assistance agencies will be able to reduce the level of attention and resources devoted to the detail of project planning and implementation. This should free their staffs to give greater attention to the considerations of macro and sector policy that will influence the economic viability of infrastructure project investment.

\section{Investment in Human Resource Development}

Both the development theorists and the development assistance agencies were slow to recognize the importance of investment in education and in other forms of human capital for economic growth. In the early literature the dominant view was that education and health programs should be considered primarily as enhancing consumption rather than as productive investments. It was generally held that such programs should be subordinated to the goal of expanding production until the country had achieved a substantial increase in the level of per capita income.

As evidence indicating high rates of return to education began to accumulate, perspectives began to change. The U.S. development assistance agency made major investments in university development in India in the 1960s. The World Bank made its first educational loan in 1963. By 1980 it had financed over 200 educational development projects. Initial emphasis was placed primarily on scientific and technical education because of its 
obvious complementarity with infrastructure, industrial, and agricultural development projects. Continuing research has indicated, however, that the highest rates of return are often at the primary level and decline as the level of educational attainment increases. Evidence from a large number of studies suggests that returns at all levels of education are substantially higher than the rate of return levels used to justify investment in many other project areas by development assistance agencies (Psacharopoulos, 1985).

There remain a number of unanswered questions. Some relate to the relative importance and efficiency of formal primary and secondary education in developing countries. There is as yet little evidence that the development assistance agencies have been especially effective in attempts to improve the efficiency of primary and secondary education programs. This stands in sharp contrast to the contributions that both private and official assistance has made to the modernization and reform of higher education in a number of countries.

\section{Returns to Agricultural Research}

Agricultural research has consistently achieved rates of return that are among the highest available to either national governments or development assistance agencies. These high social rates of return reflect substantial underinvestment in agricultural research. Underinvestment by both the private and the public sectors reflects the large spillover effects that transfer the gains from the public and private suppliers of technology to producers, and from producers to consumers.

Sustained growth in agricultural production capacity requires a careful articulation of public and private sector support for technology 
research and development. The development of public sector institutions capable of training agricultural scientists and technicians is essential. Countries that have been successful in sustaining rapid technical change in agriculture have found it necessary to develop sufficient public sector capacity in agricultural research to enable them to develop and adapt agricultural technology suited to their own resource and institutional environments. India's relatively sophisticated agricultural research system has been an important factor enabling India to confound much of expert opinion and achieve close to self-sufficiency in food grain production in the late 1970 s and early 1980s. Assistance by the U.S. aid agencies and by private foundations played an important role in strengthening India's capacity in agricultural education and research.

Those countries that have attempted to rely primarily on borrowed technology have rarely developed the capacity to adapt and manage the borrowed technology in a manner capable of sustaining agricultural development. The private sector has generally been more effective in the development and adoption of mechanical and chemical technology than of biological technology for crop and animal production. In contrast, the private sector has in most countries been relatively efficient in embodying new knowledge in technical inputs (machines, fertilizer, pesticide, seeds) and in marketing agricultural supplies compared to the public sector or parastatal organizations.

\section{Rural Development Programs}

The implementation of community and integrated rural development programs has been a continuing challenge and a source of frustration to development assistance agencies. ${ }^{4}$ The development of rural communities 
represented an important program thrust of both private and official development assistance in the 1950s. The integrated rural development thrust of the 1970s represented a renewed commitment to these same objectives. Yet the gap between the hopes for such programs and program accomplishments has remained large.

A review of the literature suggests that one of the major sources of disillusionment on the part of donors with the results of assistance to community development is a lack of consistency between the dynamics of community development processes and the imperatives of donor assistance. Successful rural development programs tend to be (a) small in geographic scope and slow to implement; (b) intensive in demands on professional and administrative capacity; (c) difficult to assess within the framework of conventional cost-benefit analysis; and (d) difficult to monitor and inspect. Donors on the other hand are under pressure to undertake large projects with measurable short-run accomplishments. They are more comfortable in dealing with projects that are (a) capital- and importintensive, (b) amenable to cost-benefit or cost-effective project analysis, and (c) easy to monitor and evaluate.

A second source of disillusionment has been the difficulty of achieving consistency between the local self-help and resource mobilization philosophy of rural development programs and the objectives of donors to achieve measurable improvements in basic human needs indicators. This has led to a program drift toward delivery of services to local communities and a neglect of the economic and political reforms necessary to achieve effective mobilization of community resources. This in turn tends to lead to a decline in program performance when donor resources are phased out. 
improvements in the level of services were often not complemented by growth in the community resources necessary to sustain the services. There is now relatively good documentation, much of it from USAID program evaluation studies, that success in local resource mobilization is an exceedingly important factor in accounting for continued program viability following the phasing-out of donor support.

Although development assistance agencies have found it difficult to achieve success in programs designed to enhance the quality of life in rural areas, one cannot conclude that there is an inherent conflict between growth and equity objectives in rural development. Indeed, the literature suggests that these objectives are potentially highly complementary. The constraint on the effectiveness of development programs has been due to the complex interaction between political and economic development at the local level that is required to generate effective demand and to sustain that demand.

\section{Some Development Assistance Policy Issues and Questions}

In the previous sections of this paper a number of rather clear-cut "lessons" from development assistance were identified. In this section I raise an issue that has recefved little attention in the literature: What development assistance activities are feasible in an unstable economic and political environment? I also return to the question of the role of various forms of assistance. Finally, I indicate some concerns about major limitations in the literature on development assistance impact. 


\section{Assistance in an Unstable Environment}

One of the most difficult problems of development assistance policy is how to provide effective assistance in an unfavorable economic and political environment. Should the development assistance community simply conclude that, where the environment for development assistance is so adverse, assistance should be discontinued until a political and administrative environment emerges that is more conducive for efficient use of development assistance?

There are at least some tentative indications from the experience of the countries studied in this review and in other literature that there are a number of areas where it is possible for development assistance to be at least moderately "policy proof"--where assistance can be designed to make an effective contribution in spite of (a) the limited effectiveness or even perversity of the policies pursued by national governments and (b) the absence of a realistic chance that government will improve the policy setting in the foreseeable future. These activities fall under the broad headings of investment in human capital and community infrastructure.

Programs to achieve the minimum levels of investment in human capital and in community infrastructure do not need to draw heavily on external resources. Institutional innovations that provide incentives for local units of government to mobilize indigenous labor and material resources should be encouraged. With support for institutional development or reform most of the resources needed to support such activities can be mobilized at the local or regional level. Such programs are usually regarded as desirable even by national governments that do not have the bureaucratic capacity, or that are too corrupt, to effectively implement larger-scale 
agricultural or industrial development projects. In many cases such programs may be more effectively carried out through either expatriate or indigenous private voluntary organizations rather than being directly administered by bilateral or multilateral assistance agencies.

In addition to the immediate benefits there are also substantial longer-term benefits from strengthening the capacity of provincial and local institutions to manage and sustain investments in human capital and community infrastructures. Development of local institutional capacity can also contribute to the development of political, bureaucratic, and technical skills that are necessary for more efficient and response national political regimes. When a more effective national regime does emerge, the local institutional infrastructure needed to sustain rapid development is in place--as in Korea after the fall of the Rhee government. Finally, considerable experimentation is often necessary to create viable institutions capable of sustaining the necessary investment in human capital and community infrastructure. A period of trial and error is often necessary to develop systems that are sustainable in terms of community economic resources and that are compatible with local cultural endowments.

\section{Aid Instruments}

Most governments are open to a policy dialogue that can take place at different levels and through the use of various aid instruments. The literature is properly inconclusive on whether program aid or project aid is the superior development policy instrument. A careful reading of the literature leads to the conclusion that an effective assistance program will include in its portfolio both program and project assistance and a variety of sectoral aid. At one extreme, nonproject aid can play a 
strategic role in providing foreign exchange and budgetary support for a government that is attempting a major structural readjustment as part of a program of policy reform. Such assistance can also play an important role in legitimizing a donor-recipient dialogue concerning the elements of the macroeconomic reform package. A level of professional capacity on the part of both the donor agency and the recipient government that commands the respect of both sets of participants in the policy dialogue is an essential element. We are sensitive to situations in which donors have forced inappropriate or inadequate policy reforms on reluctant recipients, not because of the weight of the donor policy analysis, but because of the need for assistance on the part of the recipient. And, we are also aware of situations in which the recipient countries have accepted, in principle, highly appropriate donor policy recommendations but have failed to articulate the rationale for the policies within their own political and bureaucratic environment.

At the other extreme, project assistance is more appropriate when directed toward fairly specific physical and infrastructure development projects. Transportation, communication, and sanitary and irrigation facilities are prerequisites for both rural and urban development. Primary education and health facilities and agricultural research and technology transfer capacity are essential. The capacity to construct and maintain the physical infrastructure and to staff and manage the institutional infrastructure is basic to the development process. These capacities are acquired slowly, over a generation or more, rather than during a single plan period. Project assistance can contribute to the development of the basic physical and institutional infrastructure even in environments in 
which governments have limited political or economic capacity to implement appropriate macroeconomics in sector policies. But donor assistance can also be overdone. There are situations in which donor project assistance has exceeded recipient capacity for project management. In a number of countries it appears that project assistance has contributed to the fragmentation and even the disintegration of the capacity for governance. The difficulty of providing effective sustained support for institutional development within the traditional development assistance project mechanism can be illustrated in the case of agricultural research. In a number of countries assistance for the development of national agricultural research systems has contributed to the rapid development of professional capacity and facilities. But the period of rapid development has too often been followed by the erosion or collapse of the research system's capacity when external project support has declined.

There is now a substantial body of literature that suggests that the project approach has, under a variety of circumstances, contributed to a cycle characterized by the initial development and subsequent erosion of institutional capacity. The reason is that external project assistance often provides an alternative to the development of internal political support. National program directors have frequently found that the generation of external support requires less intensive entrepreneurial effort than the cultivation of domestic political support. Development assistance agencies have given too little attention to the issues of how to provide development assistance in a manner that will strengthen rather than weaken the domestic political support for the program in which donors place high priority in their assistance efforts. 
Many assistance activities incorporate features of both program and project assistance. The key issue is not which type of assistance is in principle superior but rather which combinations of assistance forms can best promote development objectives in specific country settings. As a result, specific rules limiting or setting target allocations of different types of assistance in bilateral or multilateral institutions are distinctly inappropriate. The same is true for overall targets on local cost financing or general rules on financing solely foreign exchange components of projects.

\section{Gaps in Development Assistance Impact Analysis}

Wide gaps exist in our ability to evaluate the impact of development assistance. The evidence is most clear in those areas where both development theory and experience would lead us to expect the lowest rates of return--in the areas of physical resource transfers and capital

investment. The evidence is weakest in those areas where development theory and personal experience lead us to expect the highest rates of return. These are areas such as technical assistance, human resource investment, and institutional infrastructure development.

We are not able, for example, to document the impact on the development of individual developing countries of the very large numbers of professionals and scientists who have trained with aid support in the developing countries. Yet we are aware, when we visit the countries that have made substantial progress, that many leaders in the private sector, in higher education, and in government service have received support for their training through development assistance. 


\section{Are the Lessons Useful?}

How useful are the lessons from the past likely to be in the formulation of development assistance policy in the future? It is with considerable reluctance that I have forced myself to conclude that the lessons of the past are likely to have but limited relevance for the future.

One reason is the shift in the focus of bilateral development assistance. There is now a substantial body of evidence to the effect that donor self-interest considerations play a significantly larger role in aid allocation by bilateral donors than in the past.

In the case of the United States, strategic and foreign policy objectives account for a larger share of assistance flows than a decade or a decade-and-a-half ago. Among the other OECD countries the use of assistance resources to support donor trade and commercial policy objectives is now more important in explaining the allocation of assistance resources. This trend in bilateral assistance was partially offset by a shift toward a higher share of assistance being channeled through multilateral agencies in the 1970s. But this trend has been reversed in the 1980s.

A second reason is the decline in the share of assistance in the form of project assistance and the rise in the role of policy based assistance in the form of sector and structural adjustment lending. These loans are designed to induce and support reforms in sector policy--agricultural price policy for example--and in macroeconomic policy. Support for macroeconomic policy is not new. During the 1960 s the US/AID participated in dialogue with recipient governments such as Brazil, India and Turkey about 
macroeconomic policy and experimented with allocating performance conditions to assistance agreements. During the 1970s, however, AID narrowed its focus and concentrated more of its resources on sector development in areas such as agriculture, health, and education. The World Bank, however, from the outset, almost exclusively funded projects. Until the late 1970s the International Monetary Fund was the sole major institution engaged in extensive policy based lending. The effect of the global depression and the financial crisis that has faced large numbers of developing countries has been to propel the Bank into a rapid growth in the share of its lending in the form of sector and structural adjustment loans. The US/AID has also expanded its sector and structural adjustment lending.

This change interjects an entirely new set of criteria into the evaluation of assistance programs. Joan Nelson (1986) has emphasized that the core task of policy-based lending in support of adjustment is to create and sustain commitment (to reform) rather than to press for specific measures at a particular moment. This involves effort to bring about sustained institutional change in recipient countries rather than change physical facilities, technology, or even human capital. But neither the recipient countries or the donors are able to draw on an extensive body of experience, or theory, on how to move from the existing policy distortions to a sound macroeconomic regime characterized by an appropriate real exchange rate, appropriate incentive structures, adequate rates of domestic saving and investment, and responsible fiscal and monetary policies. The political and economic costs associated with such a transition are often very high and bear unequally on different segments of society. It is doubtful that the bilateral and multilateral donors will be able to 
generate the resources to facilitate such reforms--either in recipient countries or at home.

The third reason that I am skeptical about the value of the lessons of the past is "aid weariness" on the part of development assistance agency personnel and donor country development assistance constituencies. Assistance agency personnel are as committed, or more committed, to their work, as in the past. But in personal contact with both bilateral and multilateral assistance agency personnel, I sense that they are no longer as convinced as in the past that what they are doing will make a difference. This may reflect the more constipated economic environment of the 1980s than the buoyant atmosphere of the 1960s and 1970s. But it also reflects the lack of a new synthesis of theory and practice to provide a rationale for development assistance efforts.

I also sense a rise in skepticism among development assistance constituencies. In the United States, for example, the enthusiasm of the constituency that galvanized Congressional action and the new focus on rural development and basic needs in the 1970s has dissipated. New populist constituencies have emerged to challenge the assistance agencies on their neglect of the environmental effects of project lending. And concern with "competitiveness" have caused some former constituencies to challenge assistance for national resource, agricultural and industrial and even infrastructure development in poor countries.

What are the implications of the redirection of aid resources and aid weariness for the future of development assistance policy? I do not see the future clearly. But I do anticipate that development assistance flows and programs will differ greatly in the 1990's from the program with which 
we are familiar. One possibility is that we will see a shift from the economic assistance mode in the way developed countries relate to developing countries to an economic cooperation mode that will involve much more complex flows of resources and information. 
ENDNOTES

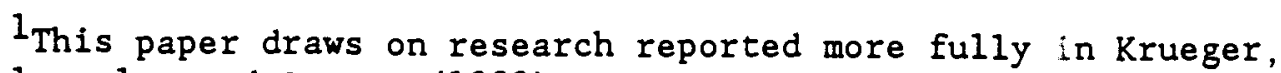
Michalopoulos and Ruttan (1989). See particularly the chapter by Sukhatme (1989).

2In the case of India, foreign aid was relatively small in the 1950 s. By the mid-1960s, it had risen to over 4 percent of India's net national product and over one-third of central government capital expenditures. By the $1980^{\prime} \mathrm{s}$, aid had fallen to about 1.5 percent of net national product and to approximately 15 percent of central government capital expenditures (Sukhatme, 1989).

3In retrospect this appears to be a case where the government was successful in blaming the donors for action that it regarded as necessary. The Indian government had thoroughly considered the devaluation of the rupee and the related changes in trade and exchange rate policies before the Bell mission report and the timing of the devaluation came as a surprise to the World Bank (Cong. 11, 1973, p. 92; Sukhatme, 1989). (1982).

${ }^{4}$ For a history of rural development programs in India, see Sussman 


\section{REFERENCES}

Q. Krueger, C. Michalopoulos and Vernon W. Ruttan (with others), Aid and Development (Baltimore: The Johns Hopkins University Press, 1989).

V. Sukhatme, "Assistance to India" in A. O. Krueger, C. Michalopoulos and Vernon W. Ruttan (eds.), Aid and Development (Baltimore: The Johns Hopkins University Press, 1989).

I. P. M. Cargill, "Efforts to Influence Recipient Performance: Case Study of India" in J. P. Lewis and I. Kupor (eds). The World Bank Group. Multilateral Aid, and the 1970s (Lexington, Mass.: Lexington Books, 1973).

G. Traxler and V. W. Ruttan "Assistance for Water Resource Development in Pakistan, Pakistan Journal of Agricultural Social Sciences 1 (July-December 1986), pp. 72-91.

G. Psacharopoulos, "Reforms to Education: A Further International Update and Implications," Journal of Human Resources 20 (1985), pp. 583-604.

G. Sussman, The Challenge of Integrated Rural Development in India (Boulder, Colo.: Westview Press, 1982).

J. M. Nelson, "The Diplomacy of Policy Based Lending" in Richard E. Feinberg (ed.) Between Two Worlds: The World Bank's Next Decade (New Brunswick: Transaction Books for Overseas Development Council), pp. 67-86.

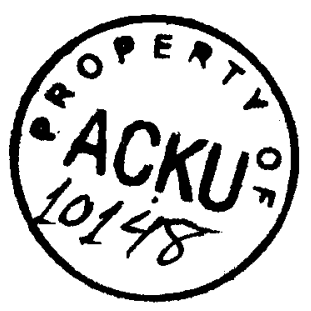

